\title{
Association between urinary sodium levels and iodine status in Korea
}

Jonghwa Ahn, Jang Ho Lee, Jiwoo Lee, Ji Yeon Baek, Eyun Song, Hye-Seon Oh, Mijin Kim, Suyeon Park, Min Ji Jeon, Tae Yong Kim, Won Bae Kim, Young Kee Shong, and Won Gu Kim

Department of Internal Medicine, Asan Medical Center, University of Ulsan College of Medicine, Seoul, Korea

Received: November 10, 2017 Revised : February 28, 2018 Accepted: March 3, 2018

\section{Correspondence to \\ Won Gu Kim, M.D.}

Division of Endocrinology and Metabolism, Department of Internal Medicine, Asan Medical Center, University of Ulsan College of Medicine, 88 Olympic-ro 43-gil, Songpa-gu, Seoul 05505, Korea

Tel: $+82-2-3010-5883$

Fax: +82-2-3010-6962

E-mail:wongukim@amc.seoul.kr
Background/Aims: To evaluate the association between the urinary sodium concentration and iodine status in different age groups in Korea.

Methods: This nationwide, population-based, cross-sectional study used data from the Korean National Health and Nutrition Examination Survey (VI 2-3, 2014 to 2015). We included 3,645 subjects aged 10 to 75 years with normal kidney function and without a history of thyroid disease. Adequate iodine intake was defined as a urinary iodine $/$ creatinine $(\mathrm{I} / \mathrm{Cr}$ ) ratio of 85 to $220 \mu \mathrm{g} / \mathrm{g}$. The urinary sodium/ creatinine $(\mathrm{Na} / \mathrm{Cr})$ ratios were classified as low $(<47 \mathrm{mmol} / \mathrm{g})$, intermediate (47 to $114 \mathrm{mmol} / \mathrm{g}$ ), or high (> $114 \mathrm{mmol} / \mathrm{g}$ ).

Results: The median urinary iodine concentration (UIC) was $292 \mu \mathrm{g} / \mathrm{L}$ (interquartile range [IQR], 157 to 672), and the median urinary I/Cr ratio was $195 \mu \mathrm{g} / \mathrm{g}$ (IQR, 104 to 478$)$. Iodine deficiency $(<100 \mu \mathrm{g} / \mathrm{L})$ and iodine excess $(>300 \mu \mathrm{g} / \mathrm{L})$ were observed in $11.3 \%$ and $49.0 \%$ of subjects, respectively. The UIC was significantly associated with the urinary sodium concentration, and the urinary I/Cr ratio was significantly correlated with the urinary $\mathrm{Na} / \mathrm{Cr}$ ratio (both $p<0.001$ ). The distributions of UIC, urinary $\mathrm{I} / \mathrm{Cr}$ ratio, and $\mathrm{Na} / \mathrm{Cr}$ ratio varied among age groups. Low urinary $\mathrm{I} / \mathrm{Cr}$ and $\mathrm{Na} / \mathrm{Cr}$ ratios were most common in young adults (age, 19 to 29 years), while high urinary $\mathrm{I} / \mathrm{Cr}$ and $\mathrm{Na} / \mathrm{Cr}$ ratios were most common in elderly people (age, 60 to 75 years).

Conclusions: Iodine intake was significantly associated with sodium intake in the Korean population. Our study suggested that an adequately low salt intake might be helpful for preventing iodine excess in Korea.

Keywords: Iodine; Sodium; Diet; Urine; Korea

\section{INTRODUCTION}

Iodine is an essential element for thyroid hormone synthesis; its deficiency and excess are associated with thyroid dysfunction and disease [1-4]. Korea is an iodine-replete area and a recent population-based study using data from the Korean National Health and Nutrition Examination Survey (KNHANES) revealed a higher iodine intake in Korea than that in many other countries [5-7].
In addition, previous studies have reported a high iodine intake among school-age children and adolescents in Korea [6,8]; the median urinary iodine concentration (UIC) in the reference Korean population was $298.5 \mu \mathrm{g} / \mathrm{L}$ (interquartile range [IQR], 160.2 to 694.1 ) and $49.9 \%$ of the population had an iodine excess status according to the World Health Organization (WHO) classification [6]. Furthermore, the UICs were higher among adolescents (median, $431.9 \mu \mathrm{g} / \mathrm{L}$ ) and old adults (median, $412.5 \mu \mathrm{g} / \mathrm{L}$ ) 
than among other age groups; however, the exact reason for the high iodine intake in these age groups is uncertain.

The major sources of dietary iodine include milk, eggs, dairy products, fish, seaweed, sea mustard, sea tangle, kelp, laver, and sea salt [9,10]. However, no study has thus far examined the association between iodine level and sea salt intake. The major source of iodine in Korea could be sea salt, as sea salt is usually used for making traditional Korean foods such as kimchi, soy sauce, and soybean paste. The sodium intake among Koreans is higher than that recommended by the WHO [11-14]. If sea salt is the major source of iodine, there may be an association between sodium intake and iodine status in Korea. A small pilot study in Korea reported lower UIC and urinary sodium concentration in the young population (age, 19 to 35 years) than those in the older population, suggesting a possible correlation between the UIC and urinary sodium concentration [15]. However, no population-based study representing Korean civilians has thus far evaluated the association between the UIC and urinary sodium concentration in different age groups. Therefore, this study aimed to evaluate the association between the iodine status and urinary sodium concentration in the Korean population using data from the KNHANES VI (2014 to 2015).

\section{METHODS}

\section{Data source and study population}

This study analyzed data from KNHANES VI-2 and VI-3 (2014 to 2015). The KNHANES is conducted by the Korean Centers for Disease Control and Prevention and is an ongoing surveillance system that assesses the health and nutritional status of the Korean population, monitors trends in health risk factors and the prevalence of major chronic diseases, and provides data for the development and evaluation of health policies and programs in Korea [7]. This nationwide, population-based, cross-sectional survey selected a representative sample of the civilian, non-institutionalized Korean population by using a stratified, multistage, clustered probability sampling design. To generate the KNHANES data, physical examinations, clinical and laboratory tests, and personal interviews were performed. From 2014 to 2015, spot urine samples were collected, and the iodine, sodium, and cre- atinine concentrations were measured.

We included subjects aged 10 to 75 years who had available data on urinary iodine, sodium, and creatinine concentrations as well as dietary sodium intake. Subjects with a serum creatinine level $>1.2 \mathrm{mg} / \mathrm{dL}$ (men) or $1.1 \mathrm{mg} / \mathrm{dL}$ (women) were excluded. A disease-free population was defined as subjects with no prior thyroid disease or thyroid cancer and no history of taking medicines that could influence thyroid function based on the results of a questionnaire survey. The KNHANES obtained written informed consent from every participant prior to completing the survey, and secondary anonymized data were used for analysis. The study protocol was approved by the Institutional Review Board of the Asan Medical Center, Seoul, Korea (2017-1353).

\section{Dietary sodium intake and urinary sodium/creati- nine ratio}

The dietary sodium intake in the KNHANES was evaluated using the 24-hour recall method with well-established questionnaires. Based on the WHO guidelines and a previous study [16], we divided the participants into three groups according to their daily dietary sodium intake levels (mg/day): <2,000, 2,000 to 5,000, and > 5,000. The urinary sodium concentration was measured using an Ion-Selective Electrode (Hitachi Automatic Analyzer 7600, Hitachi, Tokyo, Japan). To correct for the effects of urinary dilution, we used the creatinine-adjusted value as the urinary sodium/creatinine $(\mathrm{Na} / \mathrm{Cr})$ ratio $(\mathrm{mmol}[\mathrm{Na}] / \mathrm{g}[\mathrm{Cr}])$. Using the lowest and highest quantiles in the population as cutoffs, the urinary $\mathrm{Na} / \mathrm{Cr}$ ratio was categorized into three groups: low $(<47 \mathrm{mmol} / \mathrm{g})$, intermediate (47 to $114 \mathrm{mmol} / \mathrm{g}$ ), and high (>114 $\mathrm{mmol} / \mathrm{g}$ ).

\section{UICs and iodine/creatinine ratio}

The UICs were determined using inductively coupled plasma mass spectroscopy (Perkin Elmer, Waltham, MA, USA). The WHO classification defines iodine deficiency an UIC $<100 \mu \mathrm{g} / \mathrm{L}$, adequate intake/more-than-adequate as an UIC of 100 to $299 \mu \mathrm{g} / \mathrm{L}$, and an excessive iodine intake as an UIC $>300 \mu \mathrm{g} / \mathrm{L}[17]$. The urinary iodine/creatinine $(\mathrm{I} / \mathrm{Cr})$ ratio ( $\mu \mathrm{g}$ [iodine] $/ \mathrm{g}[\mathrm{Cr}])$ was used to adjust for variable water excretion rates at the time of spot urine specimen collection. A previous study showed that the urinary $\mathrm{I} / \mathrm{Cr}$ ratio had a significant diagnostic value for evaluating iodine intake [18]. In our study population, 
there was a significant association between the UIC and urinary I/Cr ratio (Supplementary Fig. 1). Values of 100 and $300 \mu \mathrm{g} / \mathrm{L}$ UIC corresponded to a urinary $\mathrm{I} / \mathrm{Cr}$ ratio of 85 and $220 \mu \mathrm{g} / \mathrm{g}$, respectively. Based on these findings, we defined the iodine status using the urinary I/Cr ratio as follows: iodine deficiency $(<85 \mu \mathrm{g} / \mathrm{g})$, adequate iodine intake ( 85 to $220 \mu \mathrm{g} / \mathrm{g}$ ), and excessive iodine intake (> $220 \mu \mathrm{g} / \mathrm{g})$.

\section{Statistical analysis}

All statistical analyses were conducted using RStudio version 1.0.153, the R library Survey, and Cairo packages (RStudio Inc., Boston, MA, USA; http://www.rstudio. com/). Using the KNHANES data-analysis guidelines, the data were weighted, stratified, and clustered. Because the KNHANES IV data were collected from 2013 to 2015, we assigned a weight of 192/384 to data for 2 years (2014 to 2015) in order to calculate the weighted frequency according to the guidelines. The weighted data were considered unbiased estimates representing the entire Korean population.

Continuous variables were presented as medians with IQRs, and categorical variables were presented as numbers with percentages. The characteristics were compared using chi-square test or multivariate logistic linear regression analysis after adjusting for age and sex. The $p$ values were two-sided, and $p<0.05$ were considered statistically significant.

\section{RESULTS}

\section{Baseline characteristics of the study subjects}

The baseline characteristics of the 3,645 subjects $(1,817$ men [52.5\%], 1,828 women [47.5\%], 29,532,753 weighted subjects) are presented in Table 1 . The median age was 41 years (IQR, 25 to 56 ); $12.0 \%$ were aged 10 to 18 years, $18.5 \%$ were 19 to 29 years, $25.2 \%$ were 30 to 44 years, $26.8 \%$ were 45 to 59 years, and $17.5 \%$ subjects were 60 to 75 years. There were 1,141 obese participants (32.0\%) (body mass index [BMI], $25 \mathrm{~kg} / \mathrm{m}^{2}$ or higher) and 694 participants (19.3\%) had hypertension. The median UIC was $292 \mu \mathrm{g} / \mathrm{L}$ (IQR, 157 to 672), and the median urinary I/Cr ratio was $195 \mu \mathrm{g} / \mathrm{g}$ (IQR, 104 to 478). Iodine deficiency (<100 $\mu \mathrm{g} / \mathrm{L}$ ) and iodine excess $(>300 \mu \mathrm{g} / \mathrm{L})$ were observed in $11.3 \%$ and $49.0 \%$ of subjects, respectively. The median daily
Table 1. Baseline characteristics of the study population in the Korean National Health and Nutrition Examination Survey VI (2014 to 2015)

\begin{tabular}{|c|c|c|}
\hline \multirow{2}{*}{ Characteristic } & \multicolumn{2}{|c|}{$\begin{array}{l}\text { Total population }(n=3,645 \\
\text { weighted } n=29,532,753)\end{array}$} \\
\hline & $\begin{array}{l}\text { No. of subjects } \\
\text { (weighted \%) }\end{array}$ & Median (IQR) ${ }^{\mathrm{a}}$ \\
\hline Age, yr & & $41(25-56)$ \\
\hline $10-18$ & $546(12.0)$ & \\
\hline $19-29$ & $626(18.5)$ & \\
\hline $30-44$ & $887(25.2)$ & \\
\hline $45-59$ & $948(26.8)$ & \\
\hline $60-75$ & $638(17.5)$ & \\
\hline \multicolumn{3}{|l|}{ Sex } \\
\hline Male & $1,817(52.5)$ & \\
\hline Female & $1,828(47.5)$ & \\
\hline Body weight, kg & & $62.2(54.5-71.5)$ \\
\hline Body mass index, $\mathrm{kg} / \mathrm{m}^{2}$ & & $23.3(20.9-25.7)$ \\
\hline$<25$ & $2,504(68.0)$ & \\
\hline$\geq 25$ & $1,141(32.0)$ & \\
\hline \multicolumn{3}{|l|}{ Hypertension $^{\mathrm{a}}$} \\
\hline Yes & $694(19.3)$ & \\
\hline No & $2,951(80.7)$ & \\
\hline Creatinine, mg/dL & & $0.8(0.7-0.9)$ \\
\hline $\begin{array}{l}\text { Dietary sodium intake, } \\
\text { mg/day }\end{array}$ & & $3,451(2,258-5,086)$ \\
\hline$<2,000$ & $729(19.1)$ & \\
\hline $2,000-5,000$ & $1,974(54.2)$ & \\
\hline$>5,000$ & $942(26.7)$ & \\
\hline Urinary sodium, mmol/L & & $113(80-150)$ \\
\hline$<80$ & $887(24.3)$ & \\
\hline $80-150$ & $1,830(50.7)$ & \\
\hline$>150$ & $928(25.0)$ & \\
\hline $\mathrm{UIC}, \mu \mathrm{g} / \mathrm{L}$ & & $292(157-672)$ \\
\hline$<100$ & $414(11.3)$ & \\
\hline $100-300$ & $1,446(39 \cdot 7)$ & \\
\hline$>300$ & $1,785(49.0)$ & \\
\hline Urinary I/Cr ratio, $\mu \mathrm{g} / \mathrm{g}$ & & $195(104-478)$ \\
\hline$<85$ & $646(18.1)$ & \\
\hline $85-220$ & $1,324(36.4)$ & \\
\hline$>220$ & $1,675(45 \cdot 5)$ & \\
\hline Urinary creatinine, $\mathrm{mg} / \mathrm{d}$ & & $154(101-220)$ \\
\hline
\end{tabular}

IQR, interquartile range; UIC, urinary iodine concentration; I/ $\mathrm{Cr}$, iodine/creatinine.

${ }^{a}$ Hypertension included those who had previously been diagnosed with hypertension or who had a systolic blood pressure greater than $140 \mathrm{mmHg}$ or more or a diastolic blood pressure greater than $90 \mathrm{mmHg}$ or more. 
Table 2. Urinary iodine and sodium concentrations in the study subjects

\begin{tabular}{|c|c|c|c|c|c|}
\hline \multirow{2}{*}{$\mathrm{UIC}, \mu \mathrm{g} / \mathrm{L}$} & \multicolumn{3}{|c|}{$\mathrm{UNa}, \mathrm{mmol} / \mathrm{L}$} & \multirow{2}{*}{ Total } & \multirow{2}{*}{$p$ value } \\
\hline & Low $(<80)$ & Intermediate (8o-150) & $\operatorname{High}(>150)$ & & \\
\hline Deficient $(<100)$ & 4.6 & 4.6 & 2.1 & 11.3 & $<0.001$ \\
\hline Adequate (100-300) & 10.4 & 20.1 & 9.2 & 39.7 & \\
\hline Excessive (>300) & $9 \cdot 3$ & 26.0 & $13 \cdot 7$ & 49.0 & \\
\hline Total & $24 \cdot 3$ & 50.7 & 25.0 & 100 & \\
\hline
\end{tabular}

Values are presented as proportion of weighted subjects (\%).

UIC, urinary iodine concentration; UNa, urinary sodium concentration.

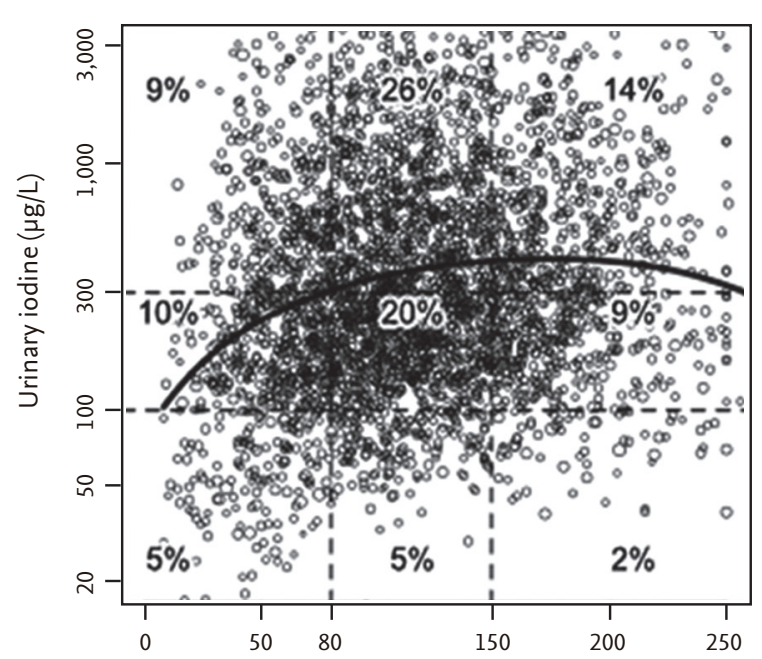

A

Urinary sodium ( $\mathrm{mmol} / \mathrm{L})$

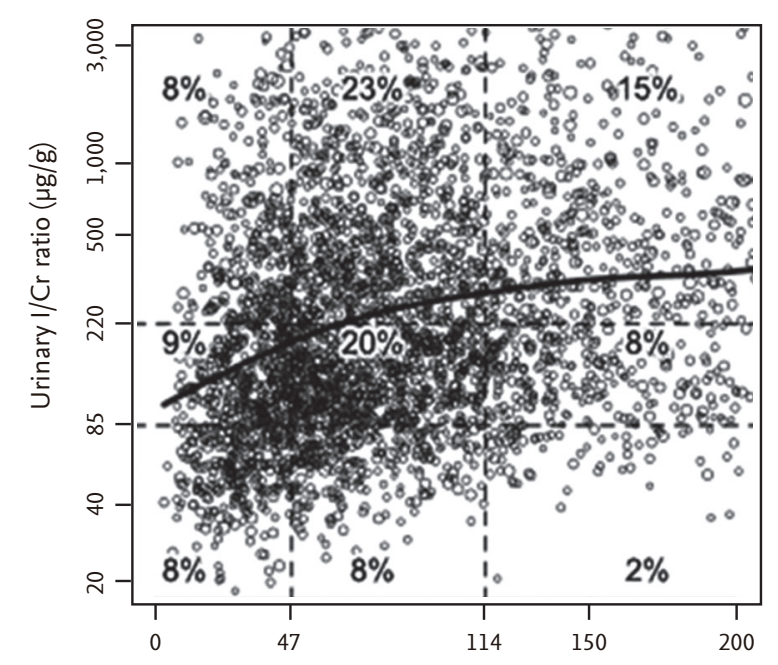

Urinary $\mathrm{Na} / \mathrm{Cr}$ ratio $(\mathrm{mmol} / \mathrm{g})$

Figure 1. Association between iodine status and sodium intake in the Korean population. (A) Distribution of urinary sodium concentration and urinary iodine concentration in the study subjects. (B) Distributions of urinary sodium/creatinine (Na/Cr) and urinary iodine/creatinine (I/Cr) ratios in the study subjects. Values represent the proportion of weighted subjects (\%) in the Korean population. Curves are generated by multivariate linear regression analysis after adjusting for age and sex.

Table 3. Urinary $\mathrm{I} / \mathrm{Cr}$ and $\mathrm{Na} / \mathrm{Cr}$ ratios in the study subjects

\begin{tabular}{|c|c|c|c|c|c|}
\hline \multirow{2}{*}{ Urine $\mathrm{I} / \mathrm{Cr}$ ratio, $\mu \mathrm{g} / \mathrm{g}$} & \multicolumn{3}{|c|}{ Urinary $\mathrm{Na} / \mathrm{Cr}$ ratio, $\mathrm{mmol} / \mathrm{g}$} & \multirow{2}{*}{ Total } & \multirow{2}{*}{$p$ value } \\
\hline & Low $(<47)$ & Intermediate (47-114) & $\operatorname{High}(>114)$ & & \\
\hline Deficient $(<85)$ & 8.2 & 7.7 & 2.2 & 18.1 & $<0.001$ \\
\hline Adequate $(85-220)$ & 8.8 & 19.7 & $7 \cdot 9$ & 36.4 & \\
\hline Excessive (> 220) & $7 \cdot 9$ & 22.7 & 14.9 & $45 \cdot 5$ & \\
\hline Total & 24.9 & 50.1 & 25.0 & 100 & \\
\hline
\end{tabular}

Values are presented as proportion of weighted subjects (\%).

I/Cr, iodine/creatinine; $\mathrm{Na} / \mathrm{Cr}$, sodium/creatinine.

sodium intake was 3,451 mg/day (IQR, 2,258 to 5,086), and the median urinary sodium concentration was 113 $\mathrm{mmol} / \mathrm{L}$ (IQR, 80 to 150).

\section{Association between UIC and urinary sodium}

There was a significant association between the UIC and urinary sodium concentration $(p<0.001$ ) (Table 2$)$. In the 


\section{KJIM}

low urinary sodium concentration group, 4.6\%, 10.4\%, and $9.3 \%$ of subjects had an iodine deficiency, adequate iodine intake, and excessive iodine intake, respectively. In the high urinary sodium concentration group, $2.1 \%$, $9.2 \%$, and $13.7 \%$ of subjects had an iodine deficiency, adequate iodine intake, and excessive iodine intake, respectively. In addition, multivariate linear regression analysis showed a significant association between the UIC and urinary sodium concentration after adjusting for age and $\operatorname{sex}(p<0.001)$ (Fig. 1A).

\section{Association between urinary $\mathrm{I} / \mathrm{Cr}$ and $\mathrm{Na} / \mathrm{Cr}$ ratios}

There was a significant association between the urinary $\mathrm{I} / \mathrm{Cr}$ and urinary $\mathrm{Na} / \mathrm{Cr}$ ratios $(p<0.001$ ) (Table 3$)$. As the urinary $\mathrm{Na} / \mathrm{Cr}$ ratio decreased, the proportion of subjects with iodine deficiency increased. In the low urinary $\mathrm{Na} /$ Cr ratiogroup, $8.2 \%, 8.8 \%$, and $7.9 \%$ of subjects had iodine deficiency, adequate iodine intake, and excessive iodine intake, respectively, whereas in the high urinary $\mathrm{Na} / \mathrm{Cr}$ ratio group, $2.2 \%, 7.9 \%$, and $14.9 \%$ of subjects had iodine deficiency, adequate iodine intake, and excessive iodine intake, respectively. Multivariate linear regression analysis showed a significant association between the urinary I/Cr and Na/Cr ratios ( $p<0.001$ ) (Fig. 1B). The clinical characteristics of sex, BMI, and hypertension in each group were described in Supplementary Tables 1 and 2.

\section{Urinary $\mathrm{l} / \mathrm{Cr}$ ratio and $\mathrm{Na} / \mathrm{Cr}$ ratio in different age groups}

Iodine deficiency (urinary $\mathrm{I} / \mathrm{Cr}$ ratio $<85 \mu \mathrm{g} / \mathrm{g}$ ) was most common in young adults (age, 19 to 29 years), whereas iodine excess (urinary I/Cr ratio $>220 \mu \mathrm{g} / \mathrm{g}$ ) was most common in the elderly (age, 60 to 75 years) (Table 4 [left]
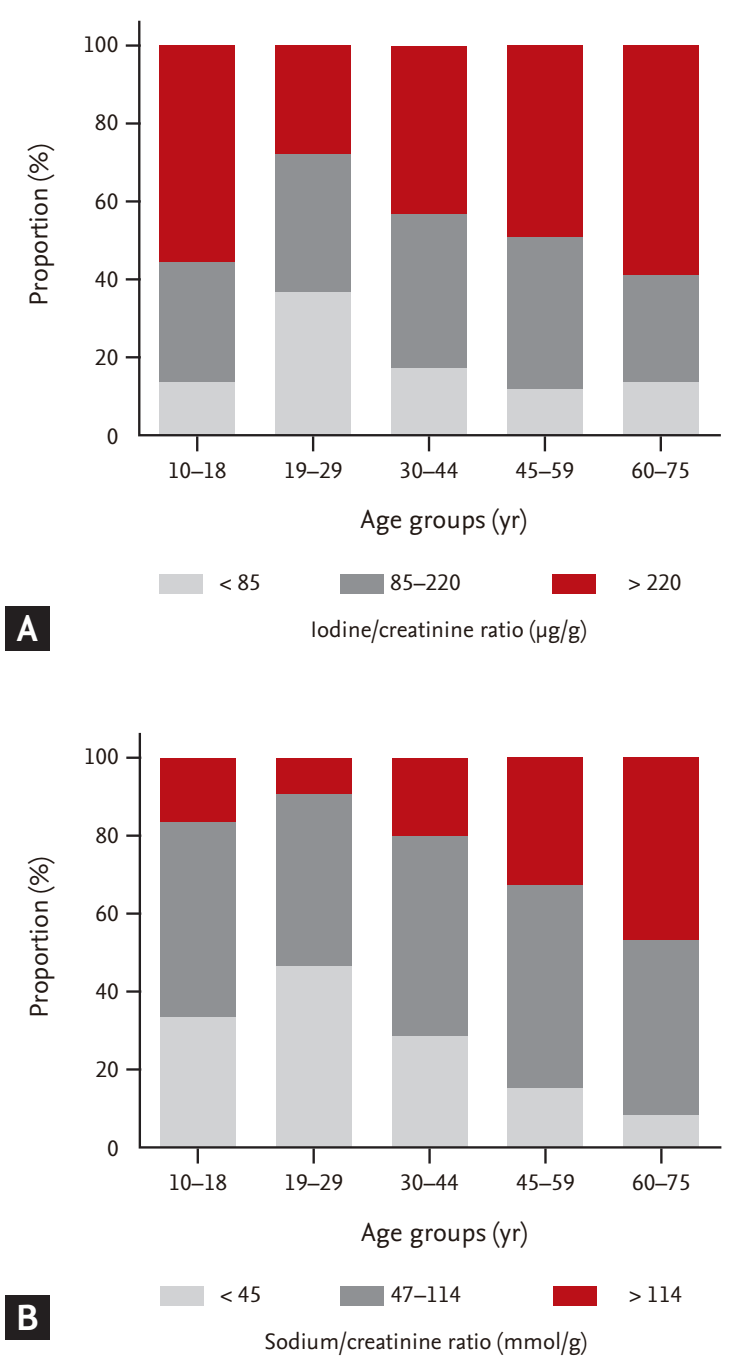

Figure 2. Urinary iodine and sodium statuses according to age in the Korean population. (A) The urinary iodine status in different age groups, estimated using the urinary iodine/ creatinine ratio. (B) The urinary sodium status in different age groups, estimated using the urinary sodium/creatinine ratio.

Table 4. Urinary $\mathrm{I} / \mathrm{Cr}$ and urinary $\mathrm{Na} / \mathrm{Cr}$ ratios according to age group

\begin{tabular}{|c|c|c|c|c|c|c|c|c|c|c|}
\hline \multirow[b]{2}{*}{ Age, yr } & \multicolumn{3}{|c|}{ Urinary I/Cr ratio, $\mu \mathrm{g} / \mathrm{g}$} & \multirow[b]{2}{*}{ Total } & \multirow[b]{2}{*}{$p$ value } & \multicolumn{3}{|c|}{ Urinary $\mathrm{Na} / \mathrm{Cr}$ ratio, $\mathrm{mmol} / \mathrm{g}$} & \multirow[b]{2}{*}{ Total } & \multirow[b]{2}{*}{$p$ value } \\
\hline & $\begin{array}{c}\text { Deficient } \\
(<85)\end{array}$ & $\begin{array}{l}\text { Adequate } \\
(85-220)\end{array}$ & $\begin{array}{c}\text { Excessive } \\
(>220)\end{array}$ & & & $\begin{array}{l}\text { Low } \\
(<47)\end{array}$ & $\begin{array}{l}\text { Intermediate } \\
\quad(47-114)\end{array}$ & $\begin{array}{l}\text { High } \\
(>114)\end{array}$ & & \\
\hline $10-18$ & $1.6(13.7)$ & $3.8(31.3)$ & $6.6(55.0)$ & $12.0(100)$ & $<0.001$ & $4.0(33.2)$ & $6.1(50.9)$ & $1.9(15.9)$ & $12.0(100)$ & $<0.001$ \\
\hline $19-29$ & $6.7(36.0)$ & $6.8(37.0)$ & $5.0(27.0)$ & $18.5(100)$ & & $8.5(46.1)$ & $8.4(45.1)$ & $1.6(8.8)$ & $18.5(100)$ & \\
\hline $30-44$ & $4.3(17.2)$ & $10.1(40.2)$ & $10.7(42.6)$ & $25.2(100)$ & & $6.9(27.4)$ & $13.6(53.9)$ & $4.7(18.7)$ & $25.2(100)$ & \\
\hline $45-59$ & $3.2(11.7)$ & $10.8(40.2)$ & $12.9(48.1)$ & $26.8(100)$ & & $4.1(15.2)$ & $14.0(52.2)$ & $8.7(32.6)$ & $26.8(100)$ & \\
\hline $60-75$ & $2.3(13.3)$ & $4.9(27.9)$ & $10.3(58.8)$ & $17.5(100)$ & & $1.4(8.0)$ & $8.0(45 \cdot 7)$ & $8.1(46.3)$ & $17.5(100)$ & \\
\hline Total & 18.1 & 36.4 & $45 \cdot 5$ & 100 & & 24.9 & 50.1 & 25.0 & 100 & \\
\hline
\end{tabular}

Values are presented as proportion of weighted subjects (\%) (proportion of subjects in different age groups, \%). I/Cr, iodine/creatinine; $\mathrm{Na} / \mathrm{Cr}$, sodium/creatinine. 
and Fig. 2A). Iodine deficiency was observed in $13.7 \%$, $36.0 \%, 17.2 \%, 11.7 \%$, and $13.3 \%$ of subjects in the 10 to 18 , 19 to 29,30 to 44,45 to 59 , and 60 to 75 years age groups, respectively $(p<0.001$ ) (Table 4 [left] and Fig. $2 \mathrm{~A}$ ) and iodine excess was observed in 55.0\%, 27.0\%, 42.6\%, 48.1\%, and $58.8 \%$ of subjects, respectively.

Similar to the urinary $\mathrm{I} / \mathrm{Cr}$ ratio, a low $\mathrm{Na} / \mathrm{Cr}$ ratio (urinary $\mathrm{Na} / \mathrm{Cr}$ ratio $<47 \mathrm{mmol} / \mathrm{g}$ ) was most common in young adults (age, 19 to 29 years) (Table 4 [right] and Fig. 2B) and a high urinary $\mathrm{Na} / \mathrm{Cr}$ ratio (> $114 \mathrm{mmol} / \mathrm{g}$ ) was most common in the elderly (age, 60 to 75 years). Low urinary $\mathrm{Na} / \mathrm{Cr}$ ratios were observed in $33.2 \%, 46.1 \%$, $27.4 \%, 15.2 \%$, and $8.0 \%$ of the subjects in the 10 to 18,19 to 29,30 to 44,45 to 59 , and 60 to 75 years age groups, respectively $(p<0.001)$ (Table 4 [right] and Fig. $2 \mathrm{~B})$ and high urinary $\mathrm{Na} / \mathrm{Cr}$ ratios were observed in $15.9 \%, 8.8 \%$, $18.7 \%, 32.6 \%$, and $46.3 \%$ of the subjects, respectively.

\section{DISCUSSION}

Recent studies using KNHANES data demonstrated that the general Korean population had a higher iodine intake those in than populations from other countries $[5,19,20]$. In one study, about half of the Korean study population had more-than-adequate or excessive iodine intake [5]. Another study suggested that the major source of dietary iodine in Korea was seaweed, as it accounted for more than $60 \%$ of the iodine intake of the Korean adults [9]. Traditional Korean foods contain sea tangle or kelp as the basic ingredient in soups, frequently brown seaweed soup and laver [21,22]. Interestingly, previous studies reported that the sodium intake of the Korean population was higher than that recommended by WHO $[11-13,15]$. In the current study, the median daily sodium intake was $3,451 \mathrm{mg}$ and the dietary sodium intake was $>2,000 \mathrm{mg}$ in $80.9 \%$ of the study population. The consumption of sea salt and other sauces containing large amounts of sea salt could be responsible for not only the high sodium intake but also the high iodine intake. To our knowledge, this is the first study to confirm the association between iodine status and sodium intake in the general Korean population.

A previous study assessed the iodine and sodium levels in the Korean population by analyzing 540 spot urine samples obtained from healthy Korean volunteers [15] and found significantly lower urinary sodium and iodine levels in young subjects (age, 19 to 35 years) than those in older subjects [15]. Another recent study reported excessive iodine intake among school-age children in Korea [8]. This cross-sectional study reported a median UIC of $458.2 \mu \mathrm{g} / \mathrm{L}$ in 373 students aged 7 to 12 years. Furthermore, $76.7 \%$ of the children had excessive iodine levels (UIC > $300 \mu \mathrm{g} / \mathrm{L}$ ), while $2.1 \%$ had iodine deficiency $(\mathrm{UIC}<100 \mu \mathrm{g} / \mathrm{L})[8]$. These studies concluded that the intake of seaweed might be responsible for the high iodine concentration, but did not assess the sodium intake.

In the current study, the distributions of UIC, urinary $\mathrm{I} / \mathrm{Cr}$ ratio, and urinary $\mathrm{Na} / \mathrm{Cr}$ ratio varied among age groups. A previous study using KNHANES data demonstrated high UICs and urinary $\mathrm{I} / \mathrm{Cr}$ ratios in the elderly (age, $\geq 60$ years) and young adolescents (age, 10 to 18 years) and low UICs and urinary I/Cr ratios in young adults (age, 19 to 29 years) [6]. However, the reason for the varied iodine intake among these age groups is uncertain. Differences in dietary habits between young adults and the elderly may be responsible for this variation. In this study, among all groups, young adults (age, 19 to 29 years) had the lowest urinary sodium and urinary $\mathrm{Na} / \mathrm{I}$ ratio and the elderly (age, 60 to 75 years) had the highest urinary sodium and urinary $\mathrm{Na} / \mathrm{I}$ ratio. These patterns of sodium intake in young adults and elderly were consistent with their UICs and urinary I/Cr ratios, which reflect the iodine intake. These findings support the significant association between sodium intake and iodine intake in the Korean population.

In this study, we evaluated the iodine intake by measuring the UIC and urinary $\mathrm{I} / \mathrm{Cr}$ ratio in the general Korean population. Since iodine absorbed in the body is primarily excreted in the urine, urinary iodine concentration reflects the iodine intake $[23,24]$. Previous studies demonstrated that the UIC in spot urine is a good indicator of the iodine nutritional status in general populations $[5,6,17,24]$. If the protein intake is adequate in healthy populations, creatinine is excreted in the urine at a relatively constant rate. To adjust for the effects of urinary dilution, the urinary $\mathrm{I} / \mathrm{Cr}$ ratio is used to evaluate the iodine status. In this study, we excluded subjects with abnormal renal function in order to accurately evaluate the iodine and sodium status in the urine samples. In addition, we determined the corresponding values of the urinary I/Cr ratio by using the WHO defi- 
nition of UICs for the iodine nutritional status (Supplementary Fig. 1).

This study showed that the iodine intake of the Korean population was higher than that reported for other countries. In our study, the median UIC was $292 \mu \mathrm{g} / \mathrm{L}$ (IQR, 157 to 672). A previous Japanese study also reported a median UIC of $281.6 \mu \mathrm{g} / \mathrm{L}$ because the geographical environment and iodine source were similar to those of Korea [25]. However, the median UIC in the US NHANES (2007 to 2008) was $164 \mu \mathrm{g} / \mathrm{L}[26]$, and that in one Dutch study was $130 \mu \mathrm{g} / \mathrm{L}[20]$. The association between the iodine nutritional status and salt intake was suggested in one study using US NHANES (2001 to 2004) data. That study showed that dietary salt restriction was associated with significant iodine deficiency only in women but not men. The prevalence of iodine deficiency in that study was $24.96 \%$ in men and $40.42 \%$ in women [27]. However, no study has reported the association between iodine nutritional status and salt intake in an iodine sufficient area.

Despite the important findings, this study had several limitations. First, this was a cross-sectional study. Therefore, the presence of a causal relationship between the iodine and sodium intakes could not be examined. Second, to evaluate the iodine status and sodium intake, spot urine samples were used instead of the 24-hour urine samples. Spot urine is widely used in national surveys because it can be easily collected and analyzed. However, a single spot urine sample is a poor predictor of sodium and iodine intake as compared to 24-hour urine samples, because the former varies even within a day and reflects only the recent intake $[28,29]$. In addition, we did not fully consider medications and gastrointestinal surgery history that may affect UICs and urinary sodium concentrations. Third, we did not evaluate the food intake of the subjects in this study. It is difficult to analyze exactly what foods contributed to our results. Nevertheless, to our knowledge, this is the first nationwide study to evaluate the possible association between iodine status and sodium intake in the Korean population.

In conclusion, there was a significant association between the iodine status and sodium intake in the Korean population. Iodine deficiency and low sodium intake were most common in young adults, whereas iodine excess and high sodium intake were most common in the elderly. Our study findings suggest that an adequately low salt intake might be helpful for preventing iodine excess in Korea. Further research is needed to confirm the causal relationship.

\section{KEY MESSAGE}

1. Iodine intake was significantly associated with sodium intake in the Korean population.

2. Iodine deficiency and low sodium intake were most common in young adults, whereas iodine excess and high sodium intake were most common in the elderly.

\section{Conflict of interest}

No potential conflict of interest relevant to this article was reported.

\section{Acknowledgments}

This study was supported by the National Research Foundation (NRF) of Korea Research Grant (NRF2015R1C1A1A02036597).

\section{REFERENCES}

1. Braverman LE. Iodine and the thyroid: 33 years of study. Thyroid 1994;4:351-356.

2. Clark OH. Excess iodine intake and thyroid function and growth. Thyroid 1990;1:69-72.

3. Hwang S, Lee EY, Lee WK, Shin DY, Lee EJ. Correlation between iodine intake and thyroid function in subjects with normal thyroid function. Biol Trace Elem Res 2011;143:1393-1397.

4. Sun X, Shan Z, Teng W. Effects of increased iodine intake on thyroid disorders. Endocrinol Metab (Seoul) 2014;29:240-247.

5. Jeon MJ, Kim WG, Kwon H, et al. Excessive iodine intake and thyrotropin reference interval: data from the Korean National Health and Nutrition Examination Survey. Thyroid 2017;27:967-972.

6. Kwon H, Kim WG, Jeon MJ, et al. Age-specific reference interval of serum TSH levels is high in adolescence in an iodine excess area: Korea National Health and Nutrition Examination Survey data. Endocrine 2017;57:445-454.

7. Kim WG, Kim WB, Woo G, et al. Thyroid stimulating hor- 
mone reference range and prevalence of thyroid dysfunction in the Korean population: Korea National Health and Nutrition Examination Survey 2013 to 2015. Endocrinol Metab (Seoul) 2017;32:106-114.

8. Choi YS, Ock S, Kwon S, et al. Excessive iodine status among school-age children in Korea: a first report. Endocrinol Metab (Seoul) 2017;32:370-374.

9. Kim JY, Moon SJ, Kim KR, Sohn CY, Oh JJ. Dietary iodine intake and urinary iodine excretion in normal Korean adults. Yonsei Med J 1998;39:355-362.

10. Pearce EN, Pino S, He X, Bazrafshan HR, Lee SL, Braverman LE. Sources of dietary iodine: bread, cows' milk, and infant formula in the Boston area. J Clin Endocrinol Metab 2004;89:3421-3424.

11. Rhee MY, Shin SJ, Park SH, Kim SW. Sodium intake of a city population in Korea estimated by 24 -h urine collection method. Eur J Clin Nutr 2013;67:875-880.

12. Hong JW, Noh JH, Kim DJ. Factors associated with high sodium intake based on estimated 24-hour urinary sodium excretion: the 2009-2011 Korea National Health and Nutrition Examination Survey. Medicine (Baltimore) 2016;95:e2864.

13. Lee SK, Kim MK. Relationship of sodium intake with obesity among Korean children and adolescents: Korea National Health and Nutrition Examination Survey. Br J Nutr 2016;115:834-841.

14. Lee HS, Duffey KJ, Popkin BM. Sodium and potassium intake patterns and trends in South Korea. J Hum Hypertens 2013;27:298-303.

15. Choi J, Kim HS, Hong DJ, Lim H, Kim JH. Urinary iodine and sodium status of urban Korean subjects: a pilot study. Clin Biochem 2012;45:596-598.

16. Kim Y, Kim HY, Kim JH. Associations between reported dietary sodium intake and osteoporosis in Korean postmenopausal women: the 2008-2011 Korea National Health and Nutrition Examination Survey. Asia Pac J Public Health 2017;29:430-439.

17. World Health Organization; UNICEF; ICCIDD. Assessment of iodine deficiency disorders and monitoring their elimination: a guide for programme managers, $3 \mathrm{rd} \mathrm{ed}$ [Internet]. Geneva: World Health Organization, 2007 [cited 2018 Apr 10]. Available from: http://apps.who.int/iris/bitstr eam/10665/43781/1/9789241595827_eng.pdf.

18. Kim HK, Lee SY, Lee JI, et al. Usefulness of iodine/creatinine ratio from spot-urine samples to evaluate the effec- tiveness of low-iodine diet preparation for radioiodine therapy. Clin Endocrinol (Oxf) 2010;73:114-118.

19. Hollowell JG, Staehling NW, Hannon WH, et al. Iodine nutrition in the United States. Trends and public health implications: iodine excretion data from National Health and Nutrition Examination Surveys I and III (1971-1974 and 1988-1994). J Clin Endocrinol Metab 1998;83:34013408.

20. van de Ven AC, Netea-Maier RT, Ross HA, et al. Longitudinal trends in thyroid function in relation to iodine intake: ongoing changes of thyroid function despite adequate current iodine status. Eur J Endocrinol 2013;170:49-54.

21. Joung JY, Cho YY, Park SM, et al. Effect of iodine restriction on thyroid function in subclinical hypothyroid patients in an iodine-replete area: a long period observation in a large-scale cohort. Thyroid 2014;24:1361-1368.

22. Lee J, Kim JH, Lee SY, Lee JH. Iodine status in Korean preschool children as determined by urinary iodine excretion. Eur J Nutr 2014;53:683-688.

23. Konno N, Yuri K, Miura K, Kumagai M, Murakami S. Clinical evaluation of the iodide/creatinine ratio of casual urine samples as an index of daily iodide excretion in a population study. Endocr J 1993;40:163-169.

24. Caldwell KL, Jones R, Hollowell JG. Urinary iodine concentration: United States National Health and Nutrition Examination Survey 2001-2002. Thyroid 2005;15:692-699.

25. Fuse Y, Saito N, Tsuchiya T, Shishiba Y, Irie M. Smaller thyroid gland volume with high urinary iodine excretion in Japanese schoolchildren: normative reference values in an iodine-sufficient area and comparison with the WHO/ ICCIDD reference. Thyroid 2007;17:145-155.

26. Caldwell KL, Makhmudov A, Ely E, Jones RL, Wang RY. Iodine status of the U.S. population, National Health and Nutrition Examination Survey, 2005-2006 and 2007-2008. Thyroid 2011;21:419-427.

27. Tayie FA, Jourdan K. Hypertension, dietary salt restriction, and iodine deficiency among adults. Am J Hypertens 2010;23:1095-1102.

28. McLean RM. Measuring population sodium intake: a review of methods. Nutrients 2014;6:4651-4662.

29. Montenegro-Bethancourt G, Johner SA, Stehle P, Neubert A, Remer T. Iodine status assessment in children: spot urine iodine concentration reasonably reflects true twenty-four-hour iodine excretion only when scaled to creatinine. Thyroid 2015;25:688-697. 
KJIM'

The Korean Journal of Internal Medicine Vol. 35, No. 2, March 2020

Supplementary Table 1. Clinical characteristics according to urine $\mathrm{Na} / \mathrm{Cr}$ ratio

\begin{tabular}{lccc}
\hline \multirow{2}{*}{ Characteristic } & \multicolumn{3}{c}{ Urinary Na/Cr ratio, mmol/g } \\
\cline { 2 - 4 } Sex & Low $(<47)$ & Intermediate $(47-114)$ & High $(>114)$ \\
Male & $480(14.5)$ & $963(27.5)$ & $374(10.4)$ \\
Female & $408(10.4)$ & $851(22.5)$ & $569(14.7)$ \\
BMI, kg/m ${ }^{2}$ & & & $624(16.5)$ \\
$<25$ & $637(17.6)$ & $1,243(33.9)$ & $319(8.6)$ \\
$\geq 25$ & $251(7.3)$ & $571(16.1)$ & \\
Hypertension & & & $321(9.2)$ \\
Yes & $107(3.0)$ & $1,493(40.9)$ & $677(17.9)$ \\
No & $781(21.9)$ & & \\
\hline
\end{tabular}

Values are presented as number of total 3,645 participants (proportion of subjects, \%).

$\mathrm{Na} / \mathrm{Cr}$, sodium/creatinine; BMI, body mass index. 
Ahn J, et al. Urinary sodium and iodine concentrations

Supplementary Table 2. Clinical characteristics according to urine $\mathrm{I} / \mathrm{Cr}$ ratio

\begin{tabular}{|c|c|c|c|}
\hline \multirow{2}{*}{ Characteristic } & \multicolumn{3}{|c|}{ Urine $\mathrm{I} / \mathrm{Cr}$ ratio, $\mu \mathrm{g} / \mathrm{g}$} \\
\hline & Deficient $(<85)$ & Adequate $(85-220)$ & Excessive $(>220)$ \\
\hline \multicolumn{4}{|l|}{ Sex } \\
\hline Male & $389(11.5)$ & $682(19.5)$ & $746(21.5)$ \\
\hline Female & $257(6.6)$ & $642(16.9)$ & $929(24.0)$ \\
\hline \multicolumn{4}{|l|}{$\mathrm{BMI}, \mathrm{kg} / \mathrm{m}^{2}$} \\
\hline$<25$ & $407(11.4)$ & $908(24.3)$ & $1,189(32.3)$ \\
\hline$\geq 25$ & $239(6.7)$ & $416(12.1)$ & $486(13.2)$ \\
\hline \multicolumn{4}{|l|}{ Hypertension } \\
\hline Yes & $103(2.7)$ & $244(6.3)$ & $347(10.2)$ \\
\hline No & $543(15 \cdot 4)$ & $1,080(30.1)$ & $1,328(35 \cdot 3)$ \\
\hline
\end{tabular}

Values are presented as number of total 3,645 participants (proportion of subjects, \%).

$\mathrm{I} / \mathrm{Cr}$, iodine/creatinine; BMI, body mass index. 


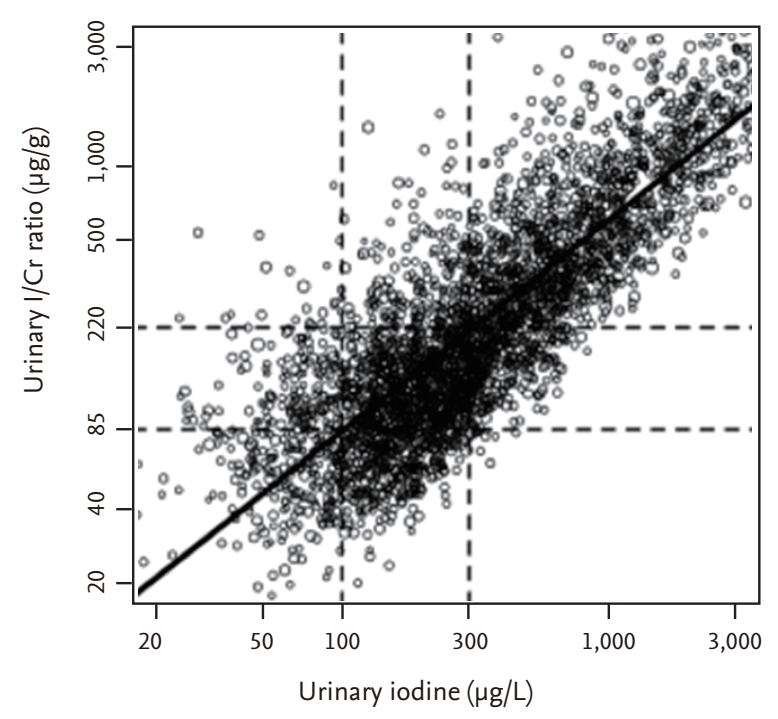

Supplementary Figure 1. Association between the urinary iodine concentration (UIC) and urinary iodine/creatinine (I/Cr) ratio in the Korean population. UICs of 100 and 300 $\mu \mathrm{g} / \mathrm{L}$ corresponded to 85 and $220 \mu \mathrm{g} / \mathrm{g}$ of urinary I/Cr ratio, respectively. Based on these findings, we defined the iodine status by using the urinary I/Cr ratio as follows: iodine deficiency $(<85 \mu \mathrm{g} / \mathrm{g})$, adequate intake ( 85 to $220 \mu \mathrm{g} / \mathrm{g}$ ), and excessive intake $(>220 \mu \mathrm{g} / \mathrm{g})$. 